2nd Department of Medicine and Cardiology Center, Medical Faculty, Albert Szent-Györgyi Clinical Center, University of Szeged

\title{
Aortic elasticity alterations in special disorders
}

\author{
Henriette Gavallér MD
}

PhD thesis

Tutor:

Attila Nemes MD, PhD 


\section{Relevant publications}

\section{Full papers}

I. Nemes A, Takács R, Gavallér H, Várkonyi TT, Wittmann T, Forster T, Lengyel C. Correlations between Arteriograph-derived pulse wave velocity and aortic elastic properties by echocardiography. Clin Physiol Funct Imaging. 2011; 31: 61-65. (Impact Factor: 1.213 )

II. Gavallér H, Sepp R, Csanády M, Forster T, Nemes A. Hypertrophic cardiomyopathy is associated with abnormal echocardiographic aortic elastic properties and arteriograph-derived pulse-wave velocity. Echocardiography. 2011; 28: 848-852. (Impact Factor: 1.239)

III. Gavallér H, Sepp R, Csanády M, Forster T, Nemes A. Evaluation of aortic distensibility by echocardiography in patients with hypertrophic cardiomyopathy. Cardiol Hung. 2011; 41: 8-12.

IV. Szolnoky G, Nemes A, Gavallér H, Forster T, Kemény L. Lipedema is associated with increased aortic stiffness. Lymphology 2012; 45: 71-79. (Impact Factor: 1.023)

V. Nemes A, Gavallér H, Hőgye M, Pálinkás A, Forster T, Csanády M. Transthoracic echocardiographic evaluation of aortic distensibility in a Takayasu's arteritis patient. $J$ Card Surg. 2006; 21: 593-595. (Impact Factor: 0.709)

\section{Abstracts}

I. Nemes A, Takács R, Gavallér H, Várkonyi T, Forster T, Lengyel C. Correlations between Arteriography-derived pulse wave velocity and aortic elastic properties by echocardiography. Eur J Echocardiography 2009; 10 (Suppl 2): ii86 
II. Nemes A, Gavallér H, Csanády M, Forster T. Abnormal echocardiographic aortic elastic properties in patients with hypertrophic cardiomyopathy. Eur J Echocardiography 2010; 11 (Suppl 2): ii21 


\section{Table of contents}

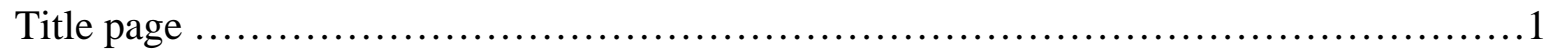

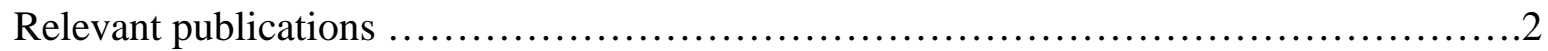

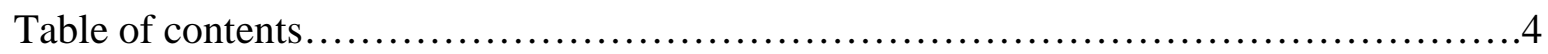

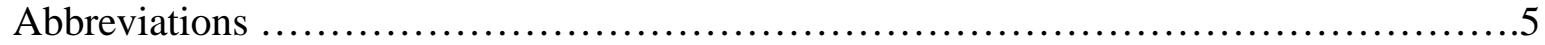

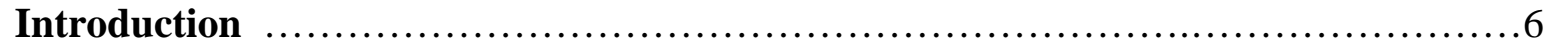

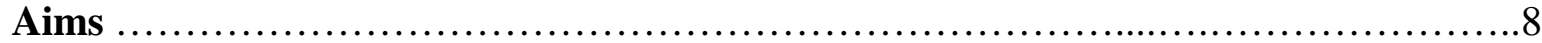

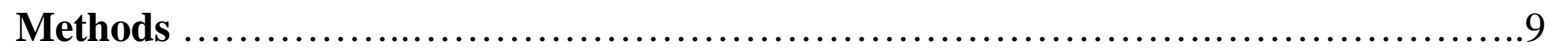

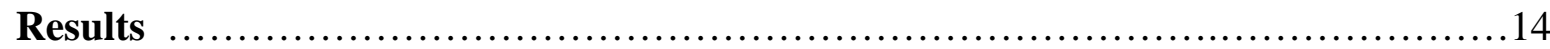

4.1. Correlations between Arteriograph-derived pulse wave velocity and aortic elastic

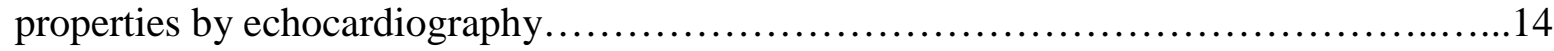

4.2. Alterations in aortic distensibility in hypertrophic cardiomyopathy..................17

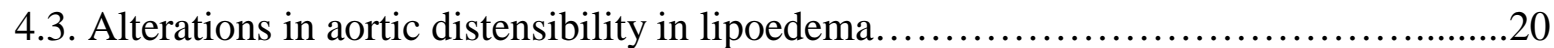

4.4. Evaluation of aortic distensibility in a patient with Takayasu's arteritis.................24

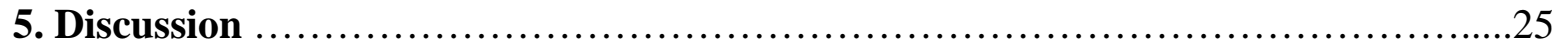

5.1. Correlations between Arteriograph-derived pulse wave velocity and aortic elastic

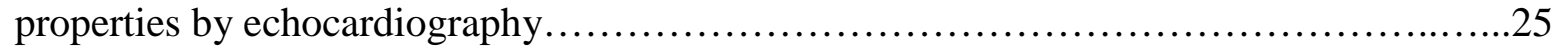

5.2. Alterations in aortic distensibility in hypertrophic cardiomyopathy $\ldots \ldots \ldots \ldots \ldots \ldots \ldots . . .26$

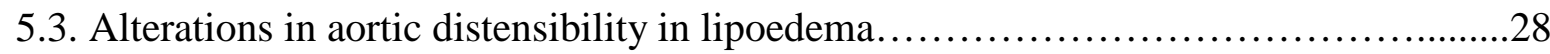

5.4. Evaluation of aortic distensibility in a patient with Takayasu's arteritis................31

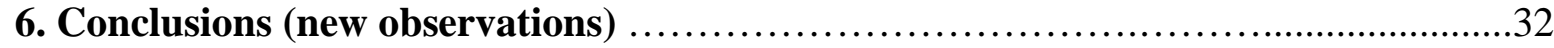

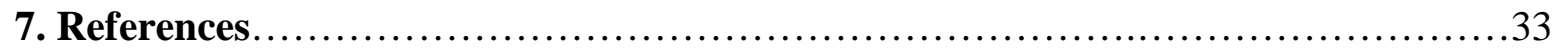

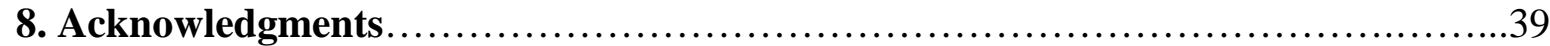




\section{Abbreviations}

ACE angiotensine-converting enzyme

Aix80 augmentation index standardized at $80 / \mathrm{min}$

ARB angiotensine-receptor blocker

BSA body surface are

$\mathrm{Ca} \quad$ calcium

DBP diastolic blood pressure

DD diastolic aortic diameter

DS systolic aortic diameter

EDD end-diastolic diameter

$\mathrm{EF} \quad$ ejection fraction

ESD end-systolic diameter

HCM hypertrophic cardiomyopathy

IVS interventricular septum

ln natural logarithm

LV left ventricular

LVM left ventricular mass

LVMI left ventricular mass index

MRI magnetic resonance imaging

PP pulse pressure

PTSMA percutanous transluminal septal myocardial ablation

PW posterior wall of the left ventricle

PWV pulse-wave velocity

PWVS35 pulse wave velocity measured at a $35 \mathrm{~mm} \mathrm{Hg}$ cuff pressure in the brachial artery

TA Takayasu's arteritis

SAM systolic anterior motion of the mitral valve

SBP systolic blood pressure

SV stroke volume 


\section{Introduction}

There is an increased scientific interest on the evaluation of parameters characterizing aortic elasticity. The healthy human aorta is not a stiff tube and could be characterized by different elastic properties. During systole, the left ventricle (LV) ejects a stroke volume (SV) into the arterial system: half of this SV is directly forwarded to the peripheral circulation, but due to peripheral resistance and elastic extension of the aortic wall the other half of the SV is stored in the aorta $(1,2)$. During diastole, the aorta recoils slowly and the stored volume is pressed into the peripheral circulation. This sort of buffering function is called as the Windkessel function (3). Normally, LV ejection causes a pressure pulse with a relatively slow pulse wave velocity (PWV). When this wave is reflected by the peripheral circulation, it returns to the ascending aorta during early diastole inducing a dicrotic wave (4). The elastic properties of the aorta incorporate both the property of dilating by increasing pressure in systole and the property of recoiling slowly to its initial shape when blood pressure falls in diastole. Aortic stiffness describes the elastic resistance that the aorta sets against its distension. The inverse of stiffness is compliance (distensibility), which describes the ease of systolic aortic expansion.

In different pathophysiologic conditions aortic stiffness increases due to fibrosis, medial smooth muscle cell necrosis, breaks in elastin fibers, calcifications or diffusion of macromolecules into the arterial wall, etc. Due to these alterations the aorta stiffens, the Windkessel function attenuates and the PWV increases $(2,3)$.

There are now two different ways to evaluate aortic distensibility: measuring PWV and augmentation index (AIx) or calculating a modulus or index, in which changes in blood pressure and aortic size during a cardiac cycle are considered (5). Measurement of PWV and AIx by Arteriograph is a new emerging tool, it has just been validated against broadly accepted tonometric and piezoelectronic methods (6). Oscillometrically measured PWV and AIx showed strong correlation with the invasively obtained values, as well (7). On the other side, echocardiography can be used for noninvasive measurement of aortic diameters, and by using forearm blood pressure values, different aortic elastic properties could be assessed. This sort of characterization of aortic stiffness has been validated against invasive measurements, and became an accepted method for more than 20 years (8). There are several debate on the 
usefulness of Arteriograph in the clinical practice, especially due to the limited number of validation studies. For instance, validation against echocardiography was missed.

Over known diseases associated with vascular complications, there are several ones, in which vascular elasticity was not widely examined:

Hypertrophic cardiomyopathy (HCM) is a genetic cardiac disease caused by a variety of mutations in genes encoding sarcomeric proteins and defined clinically by the presence of unexplained left ventricular (LV) hypertrophy with a varied clinical course and outcome (9). Vascular alterations are frequently associated with HCM including microvascular and / or peripherial endothelial dysfunction $(10,11)$. Boosanyirant et al. were the first to demonstrate increased aortic stiffness characterized by magnetic resonance imaging (MRI)-derived PWV in patients with HCM (12). However, confirmation of their results by other methods was missed in the literature.

Lipedema was firstly described by Allen and Hines more than seven decades ago but its pathomechanism remained enigmatic (13). It is a disproportional obesity, that nearly always affects women and is characterized by bilateral, symmetrical, biker's hosiery-shaped fatty swelling of the legs with sparing of the feet (14-16). Arms are also commonly affected by adipous hypertrophy. However, during progression, the characteristic "stove-pipe" legs emerge and as a result of orthostatic prolongation, a sharp demarcation between normal and abnormal tissue at the ankle with the filling of retromalleolar sulcus, giving the appearance of "pantaloon". The strongly reduced elasticity of the skin, the poor venoarterial reflex in conjunction with robust fatty enlargement substantially weaken venous calf pumps activity leading to impaired venous and lymphatic functions. Massively enlarged adipose tissue and accompanying oedema may enhance vascular resistance affecting arterial function. Some data suggest that body weight and fat distribution are related to higher arterial stiffness. These data give rise to the examination of aortic elasticity also in lipoedema.

Takayasu's arteritis (TA) is a chronic, nonspecific, and rare inflammatory disease, which segmentally affects the aorta and its main branches (17-20). However, regionality of vascular function by a non-invasive method has not been assessed in TA. 


\section{Aims}

To compare Arteriograph-derived pulse-wave velocity and augmentation index with aortic elastic properties by echocardiography

To evaluate echocardiographic ascending aortic elastic properties and Arteriograph-derived pulse-wave velocity and augmentation index in hypertrophic cardiomyopathy.

To measure aortic elasticity parameters in women with and without lipoedema.

To demonstrate the clinical usefulness of routine transthoracic echocardiography in the segmental evaluation of distensibility of ascending aorta in a patient with Takayasu's arteritis. 


\section{Methods}

Patient population (general considerations). Hundreds of patients with different disorders and control subjects were selected to evaluate the aortic elasticity alterations by echocardiography and / or Arteriograph at the 2nd Department of Medicine and Cardiology Center, University of Szeged, Hungary. A complete standard transthoracic echo-Doppler study was performed in all patients extended with aortic stiffness measurements. Diabetes mellitus was defined in accordance with the American Diabetes Association (21) and World Health Organization criteria (22). Hypertension was defined as either a systolic or a diastolic elevation of the blood pressure $(>140 / 90 \mathrm{mmHg}$ ) or ongoing antihypertensive therapy. Hypercholesterolaemia was defined as a total cholesterol level $>5.0 \mathrm{mmol} / \mathrm{l}$ or current treatment with lipid-lowering medications. The study complied with the Declaration of Helsinki. The local ethics committee of University of Szeged approved the study protocol and all patients gave informed consent.

Blood pressure measurement. Systolic and diastolic blood pressures (SBP and DBP, respectively) were measured in the supine position with an automatic mercury cuff sphygmomanometer from the left arm after $10 \mathrm{~min}$ of rest. None of the patients or control subjects used coffee or tea within one hour before blood pressure measurements and by exclusion none of the patients or control subjects were smoker.

Transthoracic echocardiography. All subjects underwent a complete two-dimensional transthoracic echocardiography and Doppler study using Toshiba Powervision 8000 and Aplio echocardiography equipments (Toshiba, Tokyo, Japan) in the left lateral decubitus position from multiple windows. All echocardiographic studies were digitally stored and evaluated by a single expert (HG) who was blinded to the clinical data. All echocardiographic measurements were averaged from 3 beats. M-mode echocardiography was used to measure LV internal dimensions. LV mass was calculated according to the Penn convention: LV mass $($ Penn $)=\left[(\text { EDD }+ \text { IVS }+ \text { PW })^{3}-\text { EDD }^{3}\right]^{*} 1.04-13.6 \mathrm{~g}$, where EDD is the LV end-diastolic diameter, IVS is the interventricular septum and PW is the LV posterior wall (23). Du Bois and Du Bois formula was used to calculate body surface area BSA $\left(\mathrm{m}^{2}\right)=0.20247 \mathrm{x}$ height $(\mathrm{m})^{0.725} \mathrm{x}$ weight $(\mathrm{kg})^{0.425}(24)$. LV hypertrophy was defined as LVM/BSA (LVMI) $>134 \mathrm{~g} / \mathrm{m}^{2}$ for men and $>110 \mathrm{~g} / \mathrm{m}^{2}$ for women (25). 
Evaluation of aortic elastic properties. Aortic elasticity parameters were calculated following a validated method (8). Systolic and diastolic ascending aortic diameters (DS and $\mathrm{DD}$, respectively) were recorded in M-mode at a level of $3 \mathrm{~cm}$ above the aortic valve from a parasternal long-axis view (Figure 1).
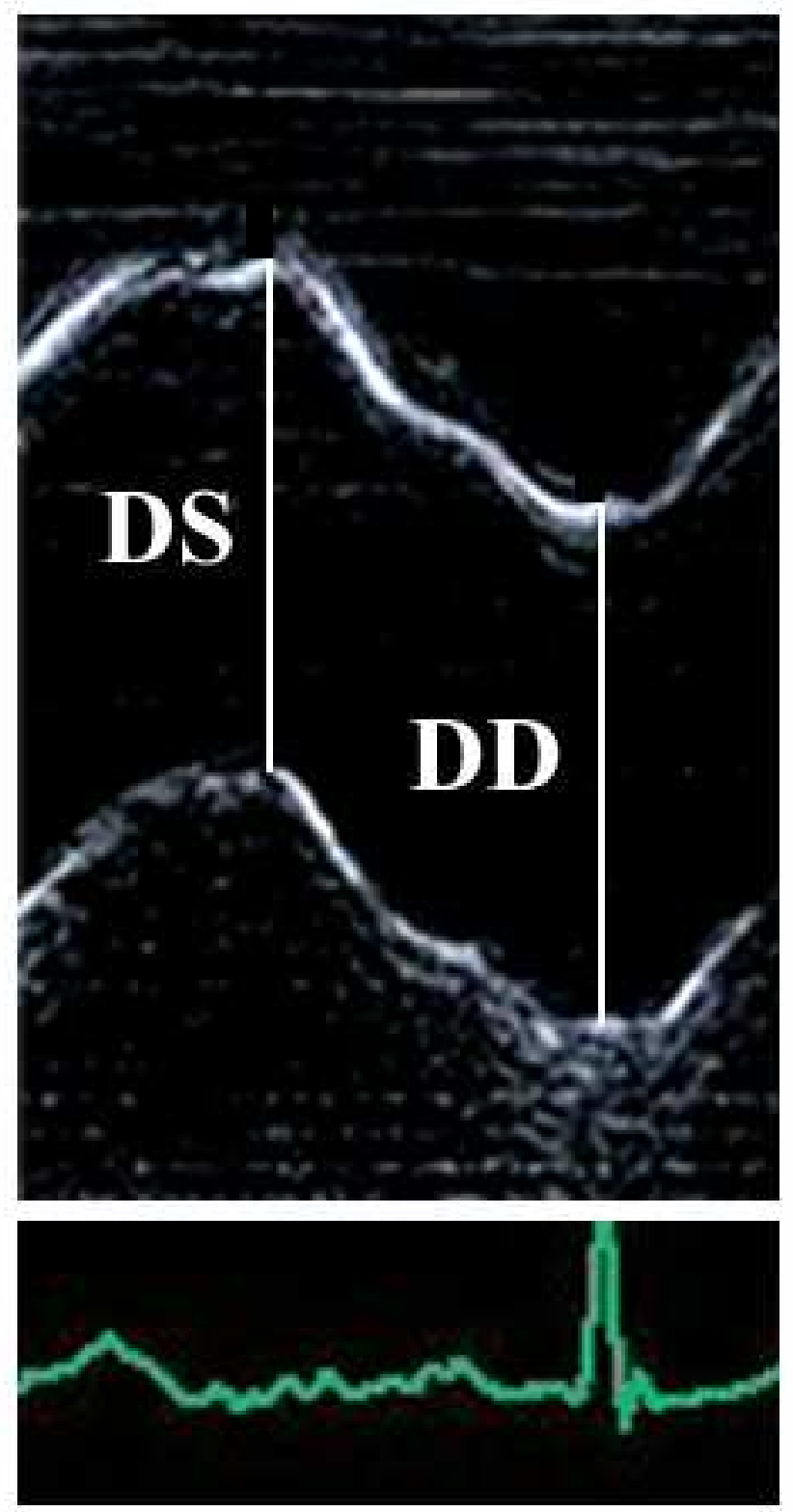

Figure 1. Measurement of systolic (DS) and diastolic (DD) diameters of the ascending aorta are shown on the M-mode tracing obtained at a level $3 \mathrm{~cm}$ above the aortic valve. 
American Society of Echocardiography convention as the most accepted border definition criteria was used measuring the leading edge of each layers. The DS and DD were measured at the time out of maximum aortic anterior motion and at the peak of QRS complex, respectively. The following aortic elasticity parameters have been calculated:

- $\quad$ Aortic strain $=(\mathrm{DS}-\mathrm{DD}) / \mathrm{DD}$

- $\quad$ Aortic elastic modulus E(p) $=($ SBP-DBP $) /[(D S-D D) / D D](26)$

- Young's circumferential static elastic modulus $\mathrm{E}(\mathrm{s})=\mathrm{E}(\mathrm{p}) * \mathrm{DD} / 2 \mathrm{~h}$, where „h” is the diastolic intima-media thickness (27)

- Aortic stiffness index $(\beta)=\ln (\mathrm{SBP} / \mathrm{DBP}) /[(\mathrm{DS}-\mathrm{DD}) / \mathrm{DD}]$, where 'In' is the natural logarithm.

- Aortic distensibility $=2 \times(D S-D D) /[(S B P-D B P) \times D D]$.

Pulse wave measurement by Arteriograph. Arteriograph is a new tool to measure PWV and Aix and just validated against other non-invasive $(6,28)$ and invasive methods (7). The Arteriograph measures the blood pressure in the upper arm by oscillometric method, and then produces a cuff pressure over the brachial artery (sytolic blood pressure measured plus $35 \mathrm{~mm}$ $\mathrm{Hg}$ ) (6). Periodic pressure changes in the inflated cuff are produced by fluctuations in pulsatile pressure in the artery under the inflated cuff. Pressure oscillations in the brachial artery are detected by the cuff, which are recorded and analysed as pulse waves by the computer. The time difference between the beginning of the first and the reflected second waves is related to the distance from the jugulum to the symphysis, and it results in the PWV in $\mathrm{m} / \mathrm{s}$. The software of the Arteriograph separates the early, late systolic and diastolic waves and the onset and the peaks of the waves are also detected. The onsets of the waves are determined by using first and second derivatives for PWV analysis. In order to intensify the signal and differentiate the initial wave from the reflective wave the Arteriograph only evaluates the pulse waves when a suprasystolic pressure of $35 \mathrm{~mm} \mathrm{Hg}$ has been attained. The augmentation index (AIx) corresponds to the pressure difference (amplitude difference; S1$\mathrm{S} 2$ ) between the first and second wave in relation to the pulse pressure (PP). The Arteriograph calculates the AIx on the basis of the formula AIx\% $=[(\mathrm{S} 2-\mathrm{S} 1) / \mathrm{PP}] \times 100$ and thus provides the brachial AIx without applying a transfer function. 


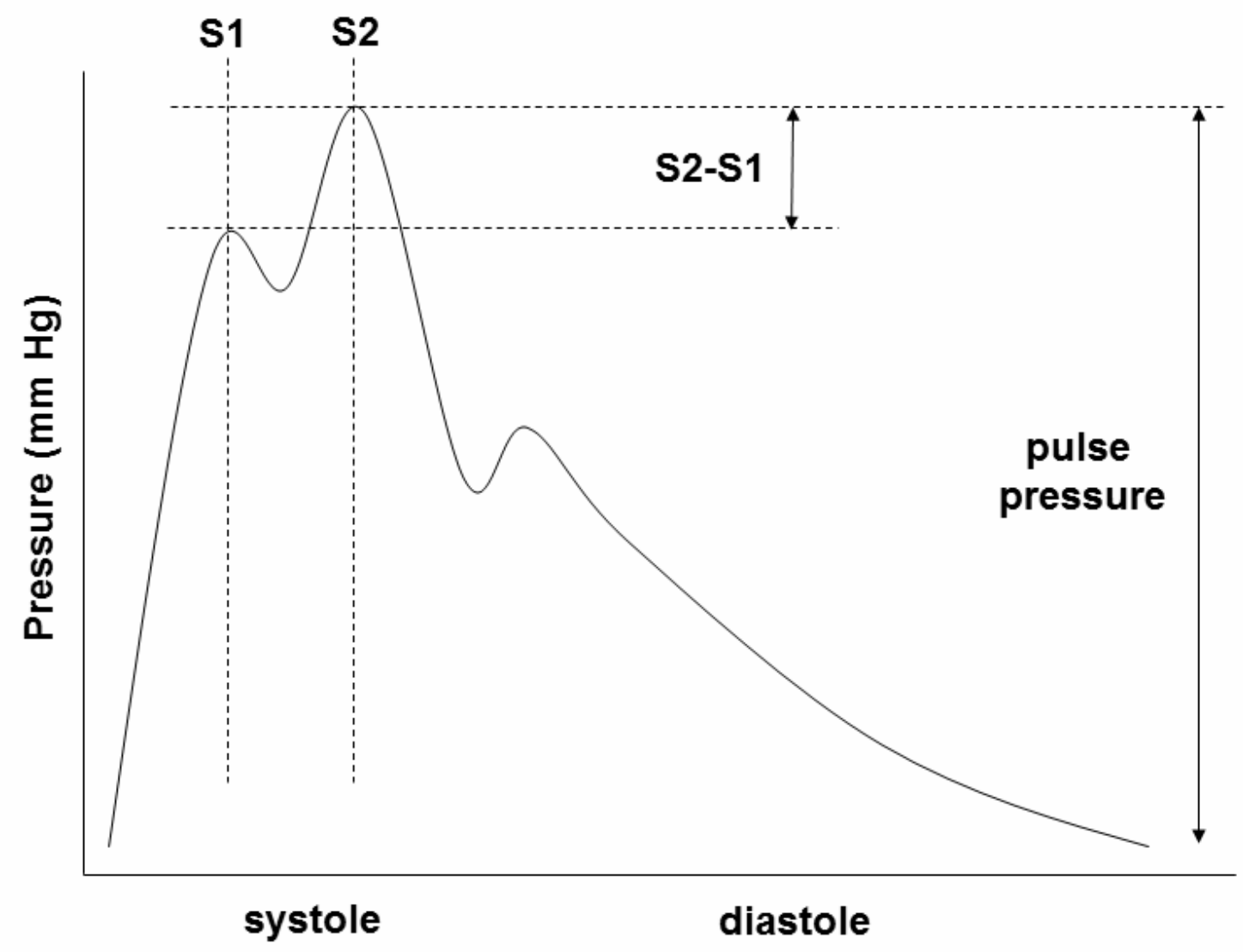

Figure 2. Oscillometric pulse wave is presented.

Abbreviations: S1: pressure peak of the initial wave in $\mathrm{mm} \mathrm{Hg}, \mathrm{S} 2$ : pressure peak of the reflected wave in $\mathrm{mm} \mathrm{Hg}$, D: diastole

Statistical analysis. Continuous data with normal distribution were presented as mean \pm standard deviation, while dichotomous data were presented as number and percentage. Between-group comparisons were made with the unpaired Student's $t$-test. For the dichotomous variables, chi-square analysis and Fisher's exact test were performed. MannWhitney test was used when needed. Numerical correlations were established by a Pearson correlation. Values for $\mathrm{R}$ were interpreted in the following way: 0.9-1: excellent, 0.7-0.89: good, 0.5-0.69: moderate, 0.3-0.49: low. Interobserver reproducibility for measuring systolic and diastolic ascending aortic diameters is 84 and $88 \%$, respectively (29). A value of $p<0.05$ 
was considered to be statistically significant. Medcalc software (Medcalc, Mariakerke, Belgium) and SPSS 12.0 and 14.0 softwares (SPSS Inc., Chicago, Illinois, USA) were used for statistical calculations. 


\section{Results}

4.1. Correlations between Arteriograph-derived pulse wave velocity and aortic elastic properties by echocardiography

Study population. The study comprised 21 healthy volunteers, their most important demographic, clinical, echocardiographic and arteriographic data are presented in Table 1. Echocardiographic parameters were normal in all subjects, none having significant valvular heart disease, segmental wall motion abnormalities or myocardial hypertrophy.

Table 1 Demographic, clinical, echocardiographic and arteriographic data of subjects

\begin{tabular}{lc}
\hline & Subjects $(\mathrm{n}=21)$ \\
\hline age (years) & $35.1 \pm 9.8$ \\
males (\%) & 38 \\
SBP (mm Hg) & $120.3 \pm 11.8$ \\
DBP (mm Hg) & $70.6 \pm 7.2$ \\
aortic PP (mm Hg) & $49.8 \pm 9.9$ \\
LV-EF (\%) & $68.5 \pm 5.7$ \\
AIx80 & $-35.8 \pm 31.9$ \\
PWVS35 (m/s) & $7.1 \pm 1.1$ \\
aortic DS (mm) & $27.8 \pm 2.3$ \\
aortic DD (mm) & $25.2 \pm 2.2$ \\
DS-DD (mm) & $2.5 \pm 0.9$ \\
Aortic strain (\%) & $10.1 \pm 3.7$ \\
Aortic distensibility $\left(\mathrm{cm}^{2} /\right.$ dynes $\left.10^{-6}\right)$ & $3.10 \pm 1.04$ \\
Aortic stiffness index & \\
\hline
\end{tabular}

Continuous variables are given as mean \pm standard deviation 
Abbreviations. AIx80: augmentation index standardized at 80/min, DBP: diastolic blood pressure, DD: aortic diastolic diameter, DS: aortic systolic diameter, LV-EF: left ventricular ejection fraction, PP: pulse pressure, PWV35: pulse wave velocity measured at a $35 \mathrm{~mm} \mathrm{Hg}$ cuff pressure in the brachial artery, SBP: systolic blood pressure

Results. Arteriograph-derived AIx80 and PWV values correlated with aortic strain $(\mathrm{R}=-$ $0.495, \mathrm{p}=0.023$ and $\mathrm{R}=-0.527, \mathrm{p}=0.014$, respectively), as it can be seen on Figure 3 .
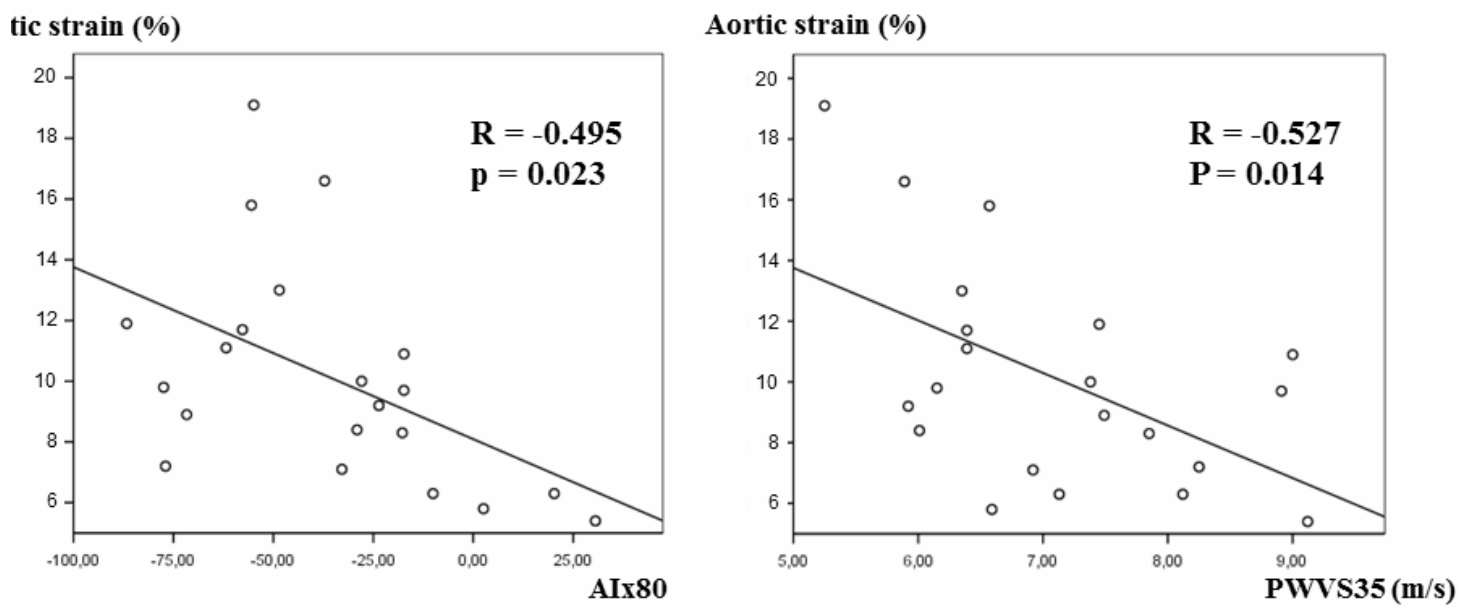

Figure 3. Correlations between aortic strain by echocardiography and pulse wave velocity and augmentation index by Arteriograph.

Aortic distensibility did not show linear correlation with AIx80 ( $\mathrm{R}=-0.344, \mathrm{p}=0.127)$, only with PWV $(\mathrm{R}=-0.593, \mathrm{p}=0.005)$ (Figure 4). 
Aortic distensibility $\left(\mathrm{cm}^{2} /\right.$ dynes $\left.10^{-6}\right)$

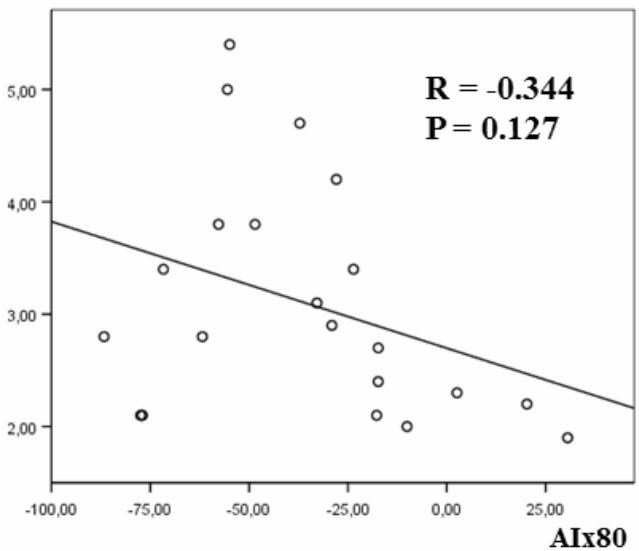

Aortic distensibility $\left(\mathrm{cm}^{2} /\right.$ dynes $\left.10^{-6}\right)$

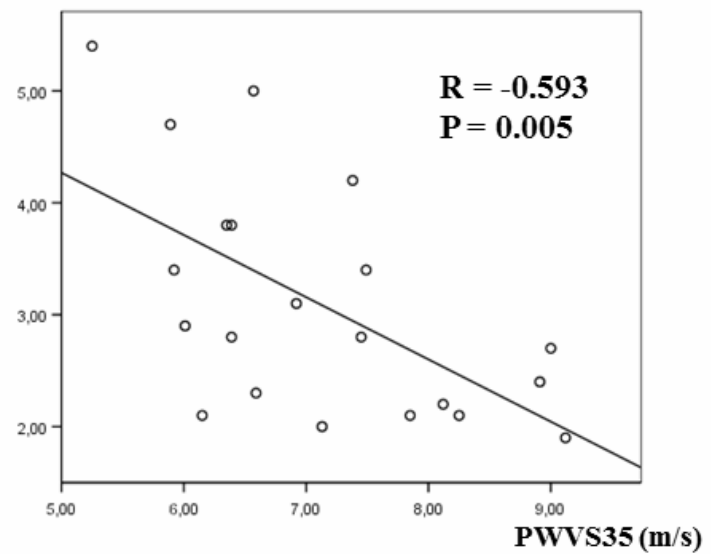

Figure 4 Correlations between aortic distensibility by echocardiography and pulse wave velocity and augmentation index by Arteriograph.

Aortic stiffness index had correlation both with AIx80 $(\mathrm{R}=0.454, \mathrm{p}=0.039)$ and PWV $(\mathrm{R}=$ $0.608, \mathrm{p}=0.003)($ Figure 5).

Aortic stiffness index

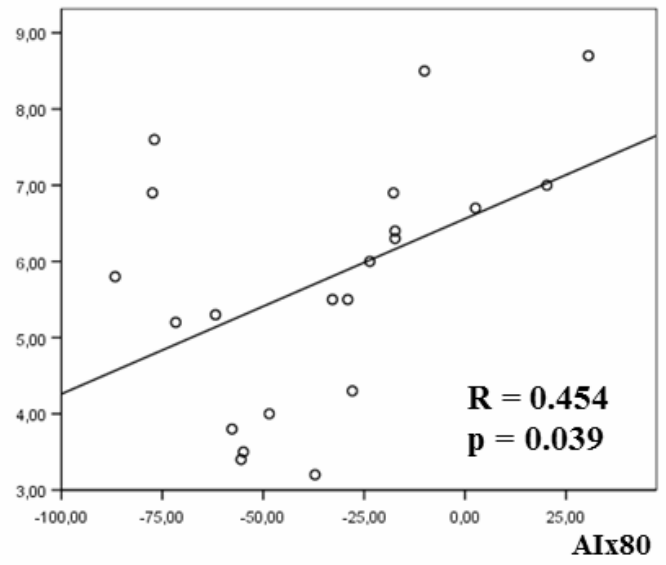

Aortic stiffness index

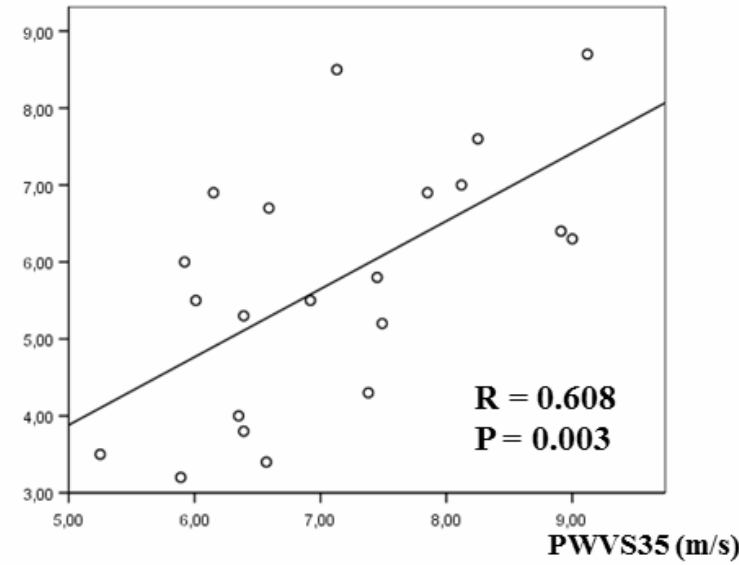

Figure 5. Correlations between aortic stiffness index by echocardiography and pulse wave velocity and augmentation index by Arteriograph. 


\subsection{Alterations in aortic distensibility in hypertrophic cardiomyopathy}

Study population. A total of 38 patients with typical features of HCM were involved into the present study. The diagnosis HCM was confirmed in all patients according to the guidelines (9). In all cases, hypertrophy was asymmetrical and had septal localization. All patients had undergone complete Doppler transthoracic echocardiographic examination to evaluate aortic elastic properties and Arteriograph-derived measurement of PWV and AIx. Their results were compared to 20 hypertensive patients with LV hypertrophy and 23 controls.

Clinical and echocardiographic data of HCM patients, hypertensive cases with LV hypertrophy and controls are presented in Tables 2-4. In HCM patients, 20 had systolic anterior motion (SAM) of the mitral valve, $8 \mathrm{had}>30 \mathrm{~mm} \mathrm{Hg}$ resting aortic gradient, 7 had ICD, 1 had prosthetic mitral valve and 4 patients were after percutaneous transluminal septal myocardial ablation (PTSMA). The mean aortic gradient in this HCM population was $29.2 \pm$ $33.5 \mathrm{~mm} \mathrm{Hg}$. LV mass was significantly increased in HCM compared to controls.

Table 2 Risk factors in HCM patients, hypertensive subject with LV hypertrophy and controls

\begin{tabular}{lccc}
\hline & $\begin{array}{c}\text { HCM } \\
\text { patients }\end{array}$ & $\begin{array}{c}\text { Hypertensive } \\
\text { patients } \\
\text { with LV } \\
\text { hypertrophy }\end{array}$ & $\begin{array}{c}\text { Controls } \\
\text { without } \\
\text { hypertension }\end{array}$ \\
\hline $\mathrm{N}$ & 38 & 20 & 23 \\
Age (years) & $47.9 \pm 17.5$ & $49.9 \pm 3.6$ & $44.1 \pm 10.9$ \\
Males (\%) & $8(21)^{* \dagger}$ & $11(55)$ & $11(48)$ \\
Diabetes mellitus $(\%)$ & $8(21)$ & $2(10)$ & $5(22)$ \\
Hypertension (\%) & $19(50)^{* \dagger}$ & $20(100)^{*}$ & $0(0)$ \\
Hypercholesterolaemia $(\%)$ & $15(39)$ & $8(40)$ & $10(44)$ \\
\hline
\end{tabular}

Continuous variables are given as mean \pm standard deviation.

$* \mathrm{p}<0.05$ vs. controls, $\uparrow \mathrm{p}<0.05$ vs. hypertensive patients with LV hypertrophy 
Table 3 Blood pressure data and medication in HCM patients, hypertensive subjects with LV hypertrophy and controls

\begin{tabular}{lccc}
\hline & HCM patients & $\begin{array}{c}\text { Hypertensive } \\
\text { patients } \\
\text { with LV } \\
\text { hypertrophy }\end{array}$ & $\begin{array}{c}\text { Controls } \\
\text { without } \\
\text { hypertension }\end{array}$ \\
\hline Blood pressure & $113.5 \pm 20.9^{\dagger}$ & $154.2 \pm 22.3^{*}$ & $123.0 \pm 8.86$ \\
Systolic blood pressure (mm Hg) & $69.5 \pm 13.0^{\dagger}$ & $89.4 \pm 11.3^{*}$ & $73.9 \pm 7.2$ \\
Diastolic blood pressure (mm Hg) & $44.1 \pm 16.9^{\dagger}$ & $64.8 \pm 18.6^{*}$ & $49.1 \pm 8.5$ \\
Aortic pulse pressure (mm Hg) & $10(26)^{* \dagger}$ & $18(90)^{*}$ & $0(0)$ \\
Medication & $12(32)^{*}$ & $10(50)^{*}$ & $0(0)$ \\
$\begin{array}{l}\beta \text {-blockers (\%) } \\
\text { ACE inhibitors or ARB }(\%)\end{array}$ & $30(79)^{*}$ & $17(85)^{*}$ & $0(0)$ \\
Ca-antagonists $(\%)$ & & & \\
\hline
\end{tabular}

Continuous variables are given as mean \pm standard deviation.

Abbreviations. ACE : angiotensine-converting enzyme, ARB : angiotensine-receptor blocker, $\mathrm{Ca}$ : calcium, HCM : hypertrophic cardiomyopathy, LV left ventricular

$* \mathrm{p}<0.05$ vs. controls, $\uparrow \mathrm{p}<0.05$ vs. hypertensive patients with LV hypertrophy

Aortic stiffness parameters. Despite blood pressure values of HCM patients were significantly lower compared to hypertensive cases, aortic elastic properties showed similar alterations compared to controls: aortic stiffness index, PWV and Aix were significantly increased, while pulsatile change in aortic diameter, aortic strain and aortic distensibility were significantly decreased in HCM patients (see Table 4). 
Table 4 Echocardiographic data and aortic stiffness parameters in HCM patients, hypertensive subjects with LV hypertrophy and controls

\begin{tabular}{|c|c|c|c|}
\hline & HCM patients & $\begin{array}{l}\text { Hypertensive } \\
\text { patients } \\
\text { with LV } \\
\text { hypertrophy } \\
\end{array}$ & $\begin{array}{c}\text { Controls } \\
\text { without } \\
\text { hypertension }\end{array}$ \\
\hline \multicolumn{4}{|l|}{ Echocardiography } \\
\hline LV end-diastolic diameter (mm) & $45.3 \pm 6.5^{* \dagger}$ & $52.6 \pm 3.6^{*}$ & $48.2 \pm 4.6$ \\
\hline LV end-systolic diameter (mm) & $26.8 \pm 7.4^{\dagger}$ & $32.2 \pm 3.8^{*}$ & $29.7 \pm 3.8$ \\
\hline LV mass index $\left(\mathrm{g} / \mathrm{m}^{2}\right)$ & $222 \pm 55^{* \dagger}$ & $150 \pm 26^{*}$ & $99 \pm 25$ \\
\hline LV ejection fraction $(\%)$ & $68.1 \pm 10.8$ & $67.9 \pm 7.3$ & $68.3 \pm 5.8$ \\
\hline Interventricular septum (mm) & $20.6 \pm 5.0^{* \dagger}$ & $11.0 \pm 1.1^{*}$ & $8.9 \pm 0.9$ \\
\hline LV posterior wall (mm) & $12.4 \pm 3.1^{* \dagger}$ & $10.6 \pm 1.0^{*}$ & $8.8 \pm 0.8$ \\
\hline Aortic systolic diameter (DS) (mm) & $31.2 \pm 4.9^{*}$ & $32.4 \pm 3.2^{*}$ & $28.9 \pm 2.1$ \\
\hline Aortic diastolic diameter (DD) (mm) & $29.5 \pm 5.1^{*}$ & $29.8 \pm 2.5^{*}$ & $26.3 \pm 2.4$ \\
\hline Pulsatile change in aortic diameter $(\mathrm{mm})$ & $1.68 \pm 1.39^{*}$ & $2.38 \pm 1.25$ & $2.53 \pm 1.39$ \\
\hline Aortic strain & $0.061 \pm 0.053^{*}$ & $0.081 \pm 0.041$ & $0.100 \pm 0.059$ \\
\hline Aortic distensibility $\left(\mathrm{cm}^{2} /\right.$ dynes $\left.10^{-6}\right)$ & $1.94 \pm 1.68^{*}$ & $2.07 \pm 1.30^{*}$ & $3.08 \pm 1.77$ \\
\hline Aortic stiffness index & $18.4 \pm 17.6^{* \dagger}$ & $9.91 \pm 8.76^{*}$ & $6.88 \pm 3.63$ \\
\hline \multicolumn{4}{|l|}{ Arteriograph results } \\
\hline PWVS35 (m/s) & $9.44 \pm 4.08^{*}$ & $10.34 \pm 2.38^{*}$ & $7.97 \pm 1.20$ \\
\hline Aix 80 & $-24.9 \pm 32.6^{*}$ & $-26.9 \pm 27.8$ & $-41.4 \pm 24.3$ \\
\hline
\end{tabular}

Continuous variables are given as mean \pm standard deviation.

Abbreviations. Aix : augmentation index standardized at 80/min, HCM : hypertrophic cardiomyopathy, LV : left ventricular, PWVS35 : pulse wave velocity measured at a $35 \mathrm{~mm}$ $\mathrm{Hg}$ cuff pressure in the brachial artery

$* \mathrm{p}<0.05$ vs. controls, $\uparrow \mathrm{p}<0.05$ vs. hypertensive patients with LV hypertrophy 


\subsection{Alterations in aortic distensibility in lipoedema}

Study population. The study comprised 14 women with and 14 without lipoedema. All of them were referred to our outpatient clinic for a routine cardiological examination, whereas lipoedema patients were first seen at the lymphedema outpatient care unit of the Department of Dermatology and Allergology (table 8 displays patient demographics). All patients underwent physical examination, 2DE and blood pressure measurement. Patients with coronary or valvular heart disease, atrial fibrillation or other arrhythmic problems, heart failure, unstable angina pectoris or acute myocardial infarction were excluded from this study. Body mass index (BMI) was calculated by dividing the participant's weight in kilograms by the square of his/her height in meters. The following classification was used: overweight (BMI 25-29.9 kg/m²), grade 1 obesity (BMI 30-34.9 kg/m²), grade 2 obesity (BMI 35-39.9 $\mathrm{kg} / \mathrm{m}^{2}$ ) and grade 3 obesity (BMI greater than $40 \mathrm{~kg} / \mathrm{m}^{2}$ ). Informed consent was obtained from each patient and the study protocol conformed to the ethical guidelines of the 1975 Declaration of Helsinki, as reflected in a prior approval by the institution's human research committee.

Results. There was no mismatch between patient and control groups from the aspect of age (40.3 \pm 9.0 vs. $35.5 \pm 8.1$ years, $\mathrm{P}>0.05)$ and mean BMI values $(27.6 \pm 1.7$ vs. $27.2 \pm 3.3$ $\left.\mathrm{kg} / \mathrm{m}^{2}, \mathrm{P}>0.05\right)$. None of them had relevant risk factors including lipid metabolism disturbance, diabetes mellitus, anemia (Table 8).

Table 8 Demographic data of lipoedema patients and controls

\begin{tabular}{lccc}
\hline & Lipoedema & Control & P value \\
\hline Age (years) & $40.3 \pm 9.0$ & $35.5 \pm 8.1$ & $>0.05$ \\
BMI (kg/m $\left.\mathbf{~}^{2}\right)$ & $27.6 \pm 1.7$ & $27.2 \pm 3.3$ & $>0.05$ \\
Diabetes mellitus (\%) & 0 & 0 & $>0.05$ \\
Lipid metabolism disorder (\%) & 0 & 0 & $>0.05$ \\
Hypertension (\%) & $4(29)$ & $3(21)$ & $>0.05$ \\
Anemia (\%) & 0 & 0 & $>0.05$ \\
\hline
\end{tabular}


Mean systolic and diastolic aortic diameters and aortic stiffness index were significantly higher, while aortic strain and distensibility were considerably lower in lipedematous patients compared to control persons (Table 9).

Table 9 Echocardiographic data, aortic dimensions and elastic properties in lipoedema patients and controls

Lipoedema group

LV end-diastolic diameter ( $\mathrm{mm})$

LV end-systolic diameter ( $\mathrm{mm})$

Interventricular septum $(\mathrm{mm})$

LV posterior wall (mm)

LV ejection fraction $(\%)$

Aortic systolic diameter (DS, mm)

Aortic diastolic diameter (DD, mm)

DS-DD (mm)

Systolic blood pressure (SBP, $\mathrm{mm} \mathrm{Hg}$ )

Diastolic blood pressure (DBP, $\mathrm{mm} \mathrm{Hg}$ )

SBP-DBP (mm Hg)

Aortic strain

Aortic distensibility ( $\mathrm{cm}^{2} /$ dynes $\left.10^{-6}\right)$

Aortic stiffness index $(\beta)$
$49.4 \pm 3.4$
$48.4 \pm 3.0$
$30.8 \pm 2.8$
$30.1 \pm 3.5$
$9.4 \pm 1.1$
$9.4 \pm 0.8$
$9.0 \pm 1.0$
$9.1 \pm 1.0$
$67.4 \pm 5.9$
$68.1 \pm 5.4$
$30.0 \pm 3.2 *$
$25.5 \pm 3.6$
$27.8 \pm 3.3 *$
$22.3 \pm 3.1$
$2.20 \pm 0.92 *$
$3.21 \pm 0.87$
$135.4 \pm 9.9$
$129.6 \pm 13.9$
$79.1 \pm 12.4$
$77.9 \pm 8.6$
$56.3 \pm 12.8$
$51.7 \pm 13.1$
$0.082 \pm 0.040 *$
$0.143 \pm 0.038$
$2.24 \pm 1.07 *$
$4.38 \pm 1.61$
$9.5 \pm 7.45 *$
$3.76 \pm 1.22$ 
Individual systolic blood pressures are displayed in Figure 7 and aortic stiffness indices are presented in Figure 8.

\section{Systolic blood pressure}

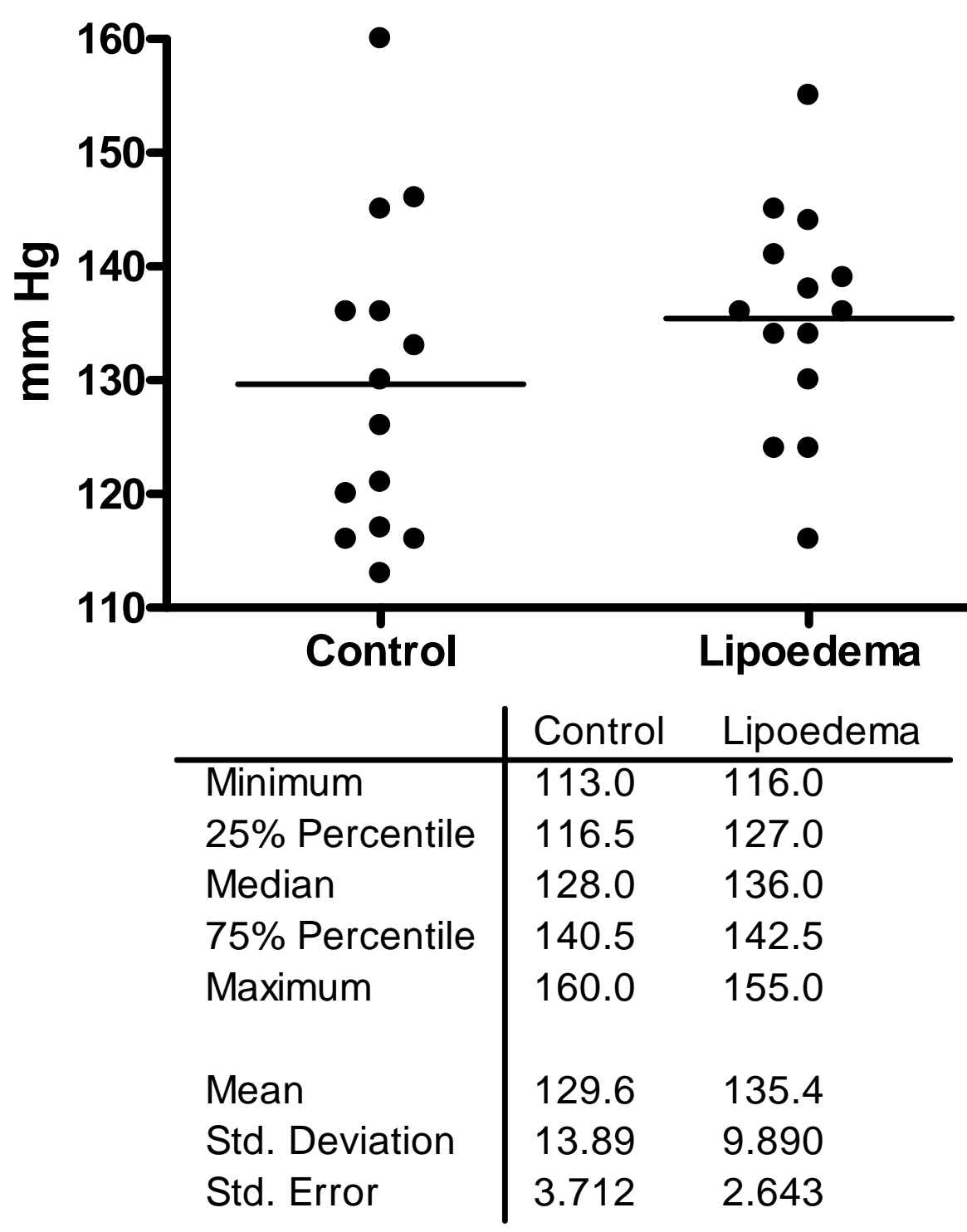

Figure 7 Individual systolic blood pressures of lipedema patients and controls 


\section{Aortic stiffness index}

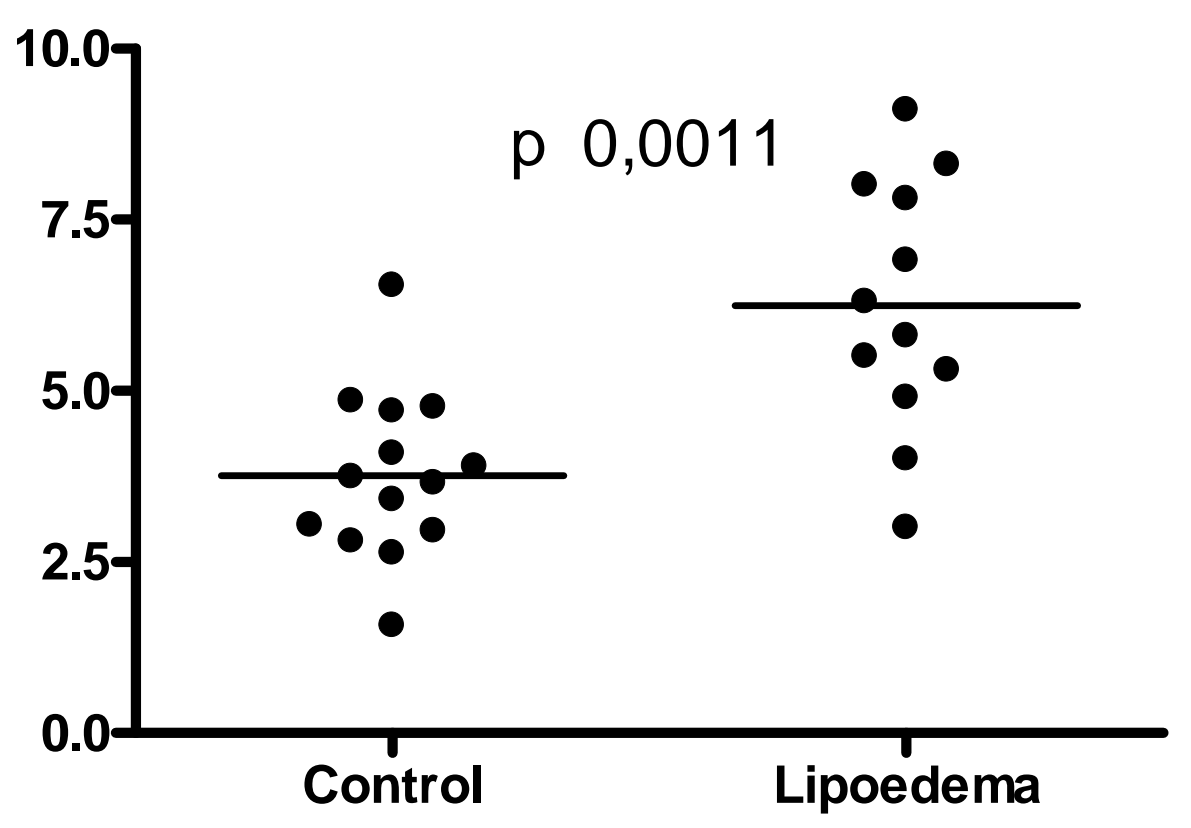

\begin{tabular}{l|ll} 
& Control & Lipoedema \\
\hline Number of values & 14 & 12 \\
& & \\
Minimum & 1.574 & 3.000 \\
25\% Percentile & 2.879 & 5.100 \\
Median & 3.699 & 6.050 \\
$75 \%$ Percentile & 4.735 & 7.900 \\
Maximum & 6.542 & 9.100 \\
& & \\
Mean & 3.761 & 6.242 \\
Std. Deviation & 1.216 & 1.842 \\
Std. Error & 0.3249 & 0.5318
\end{tabular}

Figure 8 Individual aortic stiffness indices of lipedema patients and controls (after exclusion of 2 outliners) 


\subsection{Evaluation of aortic distensibility in a patient with Takayasu's arteritis}

A 45-year-old treated hypertensive TA woman with diminished pulses was referred to the Echocardiographic Laboratory of University of Szeged. TA was diagnosed in 2003 according to the criteria established by the American College of Rheumatology (18), since she had been treated with methyl-prednisolon. At the time of her admission, digital subtractional angiography was performed showing $50 \%$ to $75 \%$ carotis communis stenoses at both sides and $>90 \%$ right subclavian arterial stenosis and total occlusion of the subclavian artery at the left side. The aortic arch and descending aorta were found to be normal. Following the steroid treatment, the symptoms (headache, arm torpidity and pain, dizziness and vomiting) regrediated. The routine 2-dimensional transthoracic echocardiographic examination showed normal left ventricular dimensions and ejection fraction. To determine aortic distensibility indices, elastic modulus [E(p)] and Young's circumferential static elastic modulus [E(s)] of the ascending aorta were evaluated $(26,27,30)$. For this purpose, systolic and diastolic aortic diameter, intimomedial thickness, and blood pressure data were measured and corrected $\mathrm{E}(\mathrm{p})$ and $\mathrm{E}(\mathrm{s})$ were calculated $(0.20$ and 2.05 , respectively) $(26,27)$. In the present case, the $[\mathrm{E}(\mathrm{p})$ in $\left.10^{3} \mathrm{mmHg}\right]$ and $\left[\mathrm{E}(\mathrm{s})\right.$ in $10^{3} \mathrm{mmHg}$ ] were decreased (aortic distensibility was practically normal) suggesting that ascending aorta was not affected by TA (31-33). 


\section{Discussion}

\subsection{Correlations between Arteriograph-derived pulse wave velocity and aortic elastic properties by echocardiography}

To the best of the authors' knowledge this is the first time to evaluate correlations between Arteriograph-derived PWV and AIx and aortic elastic properties determined by echocardiography. Low to moderate correlations were found between these parameters in healthy volunteers. Arteriograph is a relatively new emerging tool for non-invasive calculation of PWV and Aix, but not really validated recently. Aortic elastic properties by echocardiography are widely used to describe vascular distensibility and they are based on blood pressure and aortic dimension changes during cardiac cycle. The scientific experience with echocardiographic aortic stiffness measurements is based on $>1000$ international publications since 1980-90s.

The normal human aorta is not a stiff tube, it acts as an elastic buffering chamber behind the heart (3). Due to its elastic properties the aorta can dilate by increasing blood pressure in systole and can recoil to its initial shape by decreasing pressure in diastole. Aortic stiffness characterizes the elastic resistance against the distension, whereas aortic compliance describes the readiness for systolic aortic expansion. Aortic stiffness is evaluated by the change in volume due to blood injection in the aorta as well as by the pressure change induced by this volume change. Aortic stiffness can be quantified by measurement of SBP and DBP, and changes in aortic diameters (DS and DD). Transthoracic echocardiography is a routine non-invasive method for the measurement of DS and DD (29). Aortic elastic properties including aortic strain, distensibility and stiffness index can be calculated by using forearm SBP and DBP $(2,28)$. The non-invasive echocardiographic method was compared to invasive angiographic stiffness measurement technique and its accuracy was proved in patients with coronary artery disease (8).

Another noninvasive opportunity to characterize aortic stiffness is by measuring PWV and AIx. Different tonometric (SphygmoCor) and piezo-electronic (Complior) methods are used for PWV measurement (5). One of the newly validated emerging methods is Arteriograph, its based on oscillometric measurements (6). In a recent study, Arteriograph was compared with SphygmoCor and Complior, and it was concluded that PWV by Arteriograph is easy-to-use and time-effective method for assessing arterial stiffness (6). Variability and reproducibility for PWV were best for the Arteriograph, followed by 
Complior and SphygmoCor. AIx (SphygmoCor versus Arteriograph) were very closely correlated. Rajzer et al. compared PWV measurements using Complior, SphygmoCor, and Arteriograph devices, and assessed the effect of pulse wave transit time and traveled distance on PWV values (34). They found that differences in PWV obtained by compared devices resulted primarily from using various methods for measuring traveled distance and suggested uniform principles for the measurement of it. Although Arteriograph values and the determinants of PWV and AIx are in close agreement with corresponding parameters obtained by Complior and SphygmoCor, respectively, the techniques are not interchangeable (35). In contrast, lack of correlation between PWV by validated PulsePen tonometer and PWV by Arteriograph and lack of prognostic significance of PWV by Arteriograph in patients on haemodyalisis were found suggesting limited validity of Arteriograph to determine PWV (36). Moreover, simulations by Trachet et al. question the working principle of the Arteriograph. They indicate that the method picks up wave reflection phenomena confined to the brachial artery, and derived values of PWV rather reflect the stiffness of the brachial arteries (37).

The present study could be considered as a validation study comparing two different approaches to evaluate aortic stiffness. Low to moderate correlations were found between aortic elastic properties by echocardiography and Arteriograph-derived PWV and Aix80. However, further studies are warranted to validate PWV by Arteriograph against invasive methodologies.

Study limitations. This was a single-centre experience and limited by a relatively small number of healthy volunteers. The study would have been statistically stronger, if larger number of subjects had been evaluated.

\subsection{Aortic distensibility alterations in hypertrophic cardiomyopathy}

Hypertrophic cardiomyopathy, caused by mutation in one of the genes currently known to encode different components of the sarcomere, is characterized by LV hypertrophy in the absence of predisposing cardiovascular conditions (9). The clinical manifestations of HCM range from asymptomatic to progressive heart failure to sudden cardiac death and vary from individual to individual even within the same family. Recently, alterations in vascular function including increased MRI-derived PWV have been demonstrated in HCM (12). 
Elevated PWV was more pronounced in HCM patients with myocardial fibrosis. Further, aortic stiffening adversely affected LV performance. Aortic stiffness potentially has a role in evaluation of symptoms of patients with HCM. Moreover, age and PWV were found to be predictors of peak oxigen consumption $[\mathrm{pVO}(2)]$, independent of $\mathrm{LV}$ thickness, LV outflow tract gradient and diastolic indices (38). Our results are in agreement with these findings demonstrating abnormal echocardiographic aortic elastic properties and Arteriograph-derived PWV in HCM patients as compared to matched controls. Aortic elasticity parameters of hypertensive patients with LV hypertrophy were similar to HCM patients, despite HCM patients had lower blood pressure values.

Vascular alterations are often seen in HCM. It is well known, that coronary microvascular dysfunction is frequently associated with HCM, which is an independent predictor of adverse LV remodeling, systolic dysfunction, and mortality in these patients (39). Dimitrow et al. found preserved endothelial function of peripheral conductance arteries in HCM. They concluded that a defect in the forearm arterial bed in HCM seems to be limited to mechanisms maintaining the dilation of resistance vessels during decreasing reactive hyperaemia flow (40). In contrast, Heffernan et al. demonstrated impaired peripheral conduit vessel endothelial function in subjects with HCM, and the magnitude of impairment was similar to that seen in older patients with advanced coronary artery disease (11).

The precise etiology of increased aortic stiffness in HCM is uncertain. A number of factors can play a role reducing aortic distensibility in HCM including neurohormonal disturbances (increased LV pressure, activated renin-angiotensine-aldosterone system), endothelial dysfunction, abnormal LV baroreceptor stimulation, intrinsic aortic wall fibrosis etc. (11). Genetic factors and the effects of atherosclerosis and co-existing traditional cardiovascular risk factors should also be considered (41). Moreover, stiffening of the aorta may impose burden on an already stiff ventricle in HCM adversely affecting cardiac performance (11).

\section{Study limitations}

1) The blood pressure measured in the brachial artery may be different from the pressures in the ascending aorta, due to pulse pressure amplification towards the periphery. However, the results obtained by the methods used correlate well with those from invasive methods.

2) Some HCM patients had increased resting aortic gradient or were after PTSMA. There are no clinical data on the effect of obstruction on aortic stiffness in HCM. Therefore, 
further studies are warranted to examine whether differences exist in aortic elasticity parameters between HCM patients with vs. without aortic gradient. Moreover, the short and long-term effects of PTSMA on aortic elasticity should also be examined in obstructive HCM.

3) The medication used could theoretically also affect our results.

4) The available literature regarding validity of Arteriograph is limited, further validation studies are warranted.

\subsection{Aortic distensibility alterations in lipoedema}

The present study has clearly shown that aortic stiffness is increased in lipoedematous patients compared to healthy individuals within similar age group suggesting early vascular remodelling. Lipoedema is a peculiar form of adipose tissue deposition in a dysproportional fat accumulation in a biker's hosiery shape and is complicated by venous- and lymphatic insufficiency and also microangiopathy (see Figure 9)(14-16). The skin is usually normal in texture and appearance, without the dermal thickening or induration common in lymphoedema. At most, one in ten women or postpubertal girls may exhibit involvement to some degree (42). Lipoedema is presumably associated with genetic background, but, to date, none of the examined genes have proved to be responsible for the phenotypic appearance (43). It is easily distinguishable from lymphoedema and phleboedema by clinical features $(14,16,42)$, and hormonal abnormality can commonly be detected $(14,16,42)$. Lipoedema is often combined with morbid obesity, although lipoedematous tissue hardly or never responds to diet and forced weight-loss.

Generalized obesity is known to be associated with structural (altered aortic size) and functional (decreased aortic elasticity) vascular abnormalities, where aortic enlargement may represent an adaptation process to accommodate for the increased blood volume (44). Wildman et al found that excess weight begins to affect the vascular system at a very early stage of vascular aging (45). We have recently shown that obesity is associated with aortic enlargement and increased stiffness regardless the age of patients (44).

Various mechanisms can be attributed to obesity-linked aortic stiffening including visceral adipose tissue throughout insulin resistance development (46). Hyperinsulinaemia can be associated with increased sodium reabsorption (47), a stimulated sympathetic nervous system (48) and atherosclerosis (49,50). In obesity-related insulin resistant state the 
endothelium dependent vasodilator effects of insulin is weakened $(51,52)$. Higher levels of nonesterified fatty acids have been found to be associated with central obesity by increasing $\alpha$-adrenergic reactivity, vascular tone and blood pressure (53). Increased BMI has been associated with permanent low-grade inflammation and concomitantly increased expression of proinflammatory cytokines resulting in wall stiffening $(54,55)$.

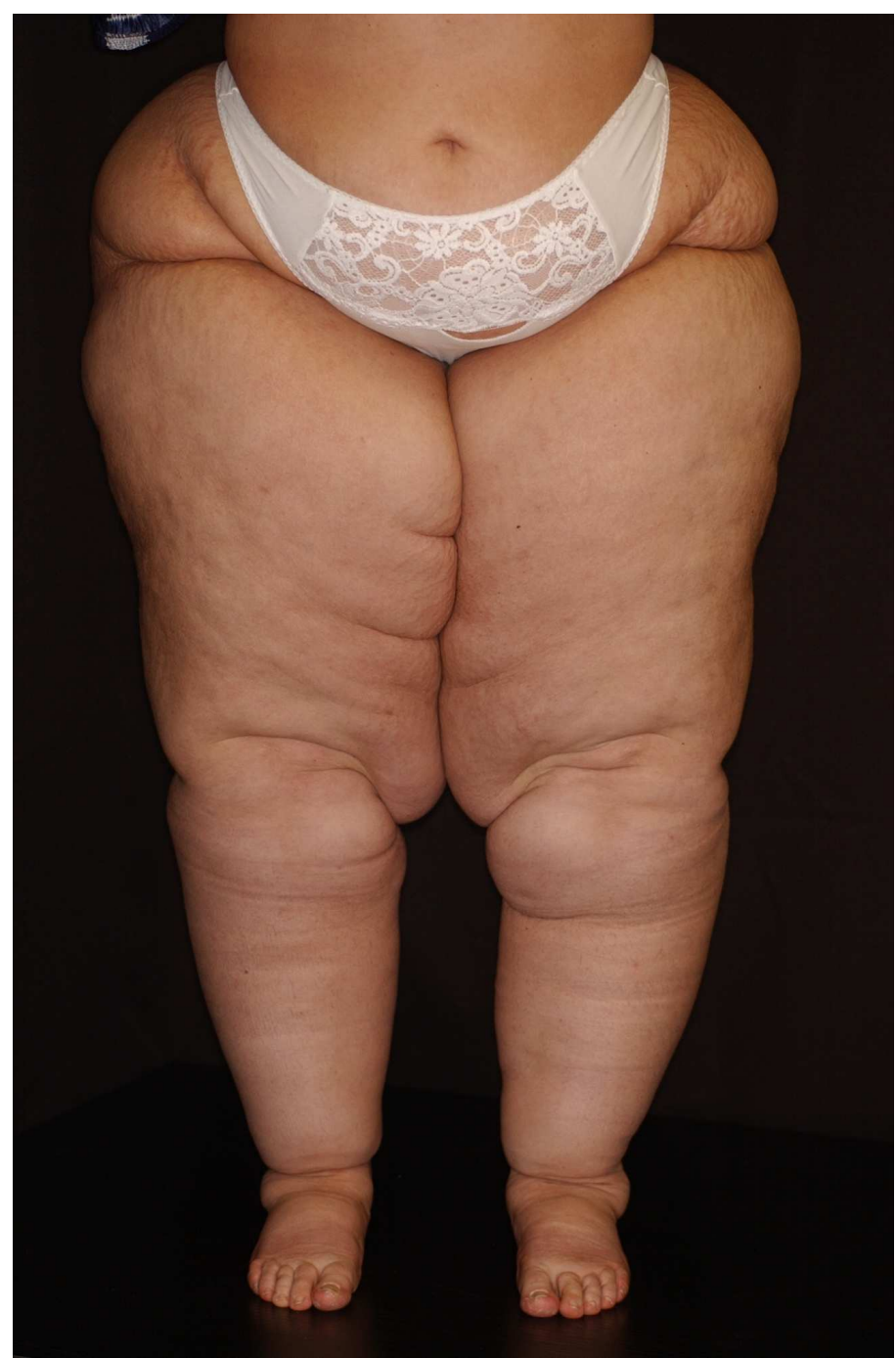

Figure 9. Lipoedema: clinical apperance

Lipoedema patients nearly always complain of spontaneous or mild injury evoked pain upon palpation that worsens with aging. Another hallmarks are frequent hematoma formation due to even minor traumatic injuries $(14,16)$ and excessive bruising. Haematoma formation is presumably triggered by increased capillary fragility (CF) and possibly by impaired venoarterial reflex (VAR) (56,57). CF measurement with a vacuum suction chamber, the Parrot's angiosterometer has clarified remarkable $\mathrm{CF}$ in the background of frequent 
haematoma formation (56). Decongestive lymphatic therapy (DLT) in combination with intermittent pneumatic compression (IPC) significantly decreased CF. Lipoedema is accompanied by local lymphatic and venous abnormalities (eg. irregularly dilated lymphatics, lymphatic microaneurysms and varicosity), major venous dysfunction is rarely found (58-60).

Several theories have been postulated regarding the etiology of lipoedema. Földi and Földi have proposed that microangiopathy in the area of the affected adipose tissue sets off the condition leading to increased permeability to proteins $(42,57)$. Hypoxia is known to be a major induction factor for angiogenesis and, in the eye, pathological angiogenesis in the retina leads to catastrophic loss of vision in retinopathy of maturity, diabetic retinopathy. The principal feature of these newly formed capillary vessels in these disorders is also fragility. Angiogenesis is controlled by several factors, including vascular endothelial growth factor (VEGF), and accordingly, abnormally high serum VEGF levels might be predicted in the presence of intensive angiogenesis and concomitant CF. A study examining effects of shockwave therapy in patients with lipoedema or cellulite found nearly 4-fold higher plasma mean VEGF level at baseline compared to non-lipoedematous individuals (61). Other observations relate to immunohistochemical findings (62). In lipoedema, adipocytes undergo necrosis and are scavenged by macrophages. Hypoxia induced by excessive adipose hypertrophy has been proposed to cause adipose metabolic dysfunction and the production of adipose tissue cytokines related to inflammatory reaction might also be operative in lipoedema. Furthermore, adipocyte enlargement and Ki67 and CD34 positivity were also observed, which are associated with cell proliferation, and adipose stem/progenitor cells, respectively.

Observed and suspected pathological features of lipoedema suggest a possible explanation for the increased aortic stiffness. Lipoedematous adipous tissue as in generalized obesity may enhance peripheral vascular resistance causing increasing aortic stiffness. Additionally, at the microvascular level, localized hypertension accompanying arteriolar remodeling and capillary hyperpermeability can lead to microangiopathy interacting with macrovascular function. Expansion of the lipoedematous microvascular network and its fragility might be explained as a compensatory response to constant stimuli from local tissue pressure and vascular resistance. Thus, the known interaction of macro- and microcirculations observed in other disorders could account for the coexistence of raised CF and aortic stiffness in lipoedema (63). 


\subsection{Evaluation of aortic distensibility in a patient with Takayasu's arteritis}

Takayasu's arteritis is a large vessel vasculitis that affects primarily women $(17,18)$. The clinical presentation depends on the location of the affected vessels and the severity of the vascular inflammation. Involvement of large vessels revealed variations; the most common angiographic finding is the involvement of the ascending aorta, the aortic arch and its main branches, and the abdominal aorta $(19,20)$. Stefanadis et al described an invasive evaluation of aortic elastic properties in TA patients (64). In the present case, for preoperative assessment, a noninvasive simple transthoracic echocardiographic method was used for the evaluation of ascending aorta distensibility (30). Neither angiography nor transthoracic echocardiography-derived aortic distensibility parameters confirmed that ascending aorta of the present case was affected by TA.

Takayasu's arteritis is an inflammatory disease affecting segmentally the large vessels. The present case suggests that for preoperative assessment, a routine transthoracic echocardiographic aortic stiffness assessment could be a valuable method for the noninvasive functional evaluation of the ascending aorta in TA. 
1. Significant correlations could be demonstrated between echocardiographic aortic elastic properties and Arteriograph-derived pulse-wave velocity and augmentation index.

2. Hypertrophic cardiomyopathy is associated with abnormal echocardiographic aortic elastic properties and Arteriograph-derived pulse-wave velocity

3. Remarkable alterations in aortic elastic properties could be demonstrated in female patients with lipoedema

4. Routine transthoracic echocardiography could be a valuable method for the noninvasive functional evaluation of the ascending aorta in Takayasu's arteritis 


\section{References}

1. Bader H. Importance of the gerontology of elastic arteries in the development of essential hypertension. Clin Physiol Biochem 1983; 1: 36-56.

2. Nemes A, Geleijnse ML, Forster $T$, Soliman OI, ten Cate FJ, Csanády M. Echocardiographic evaluation and clinical implications of aortic stiffness and coronary flow reserve and their relation. Clin Cardiol 2008; 31: 304-309.

3. Belz GG. Elastic properties and Windkessel function of the human aorta. Cardiovasc Drugs Ther 1995; 9: 73-83.

4. O'Rourke M. Arterial stiffness, systolic blood pressure, and logical treatment of arterial hypertension. Hypertension 1990; 15: 339-547.

5. Nemes A, Forster $\mathrm{T}$. Az aorta stiffness vizsgálata non-invazív módszerekkel. Metabolizmus 2009; 7: 101-105.

6. Baulmann J, Schillings U, Rickert S, Uen S, Düsing R, Illyes M, Cziraki A, Nickering G, Mengden T. A new oscillometric method for assessment of arterial stiffness: comparison with tonometric and piezo-electronic methods. J Hypertens 2008; 26: 523-528.

7. Horváth IG, Németh A, Lenkey Z, Alessandri N, Tufano F, Kis P, Gaszner B, Cziráki A. Invasive validation of a new oscillometric device (Arteriograph) for measuring augmentation index, central blood pressure and aortic pulse wave velocity. J Hypertens. 2010; 28: 2068-2075.

8. Stefanadis C, Stratos C, Boudoulas H, Kourouklis C, Toutouzas P. Distensibility of the ascending aorta: comparison of invasive and non-invasive techniques in healthy mean and in mena with coronary artery disease. Eur Heart J 1990; 11: 990-996.

9. Maron BJ, McKenna WJ, Danielson GK, Kappenberger LJ, Kuhn HJ, Seidman CE, Shah PM, Spencer WH 3rd, Spirito P, Ten Cate FJ, Wigle ED; Task Force on Clinical Expert Consensus Documents. American College of Cardiology; Committee for Practice Guidelines. European Society of Cardiology. American College of Cardiology/European Society of Cardiology clinical expert consensus document on hypertrophic 
cardiomyopathy. A report of the American College of Cardiology Foundation Task Force on Clinical Expert Consensus Documents and the European Society of Cardiology Committee for Practice Guidelines. J Am Coll Cardiol 2003; 42: 1687-1713.

10. Soliman OI, Knaapen P, Geleijnse ML, Dijkmans PA, Anwar AM, Nemes A, Michels M, Vletter WB, Lammertsma AA, ten Cate FJ. Assessment of intravascular and extravascular mechanisms of myocardial perfusion abnormalities in obstructive hypertrophic cardiomyopathy by myocardial contrast echocardiography. Heart 2007; 93: 1204-1212.

11. Heffernan KS, Napolitano CA, Maron MS, Patvardhan EA, Patel AR, Pandian NG, Karas RH, Kuvin JT. Peripheral vascular endothelial function in patients with hypertrophic cardiomyopathy. Am J Cardiol 2010; 105: 112-115.

12. Boonyasirinant T, Rajiah $P$, Setser RM, Lieber ML, Lever HM, Desai MY, Flamm SD. Aortic stiffness is increased in hypertrophic cardiomyopathy with myocardial fibrosis: novel insights in vascular function from magnetic resonance imaging. J Am Coll Cardiol 2009; 54: 255-262.

13. Allen EV, Hines EA. Lipedema of the legs: a syndrome characterized by fat legs and orthostatic edema. Mayo Clin Proc 1940; 15: 184-187.

14. Langendoen SI, Labbema L, Nijsten TE, Neumann HA. Lipoedema: from clinical presentation to therapy. A review of the literature. Br J Dermatol 2009; 161: 980-986.

15. Szolnoky G, Kemény L. Lipoedema: from clinical presentation to therapy. Further aspects. Br J Dermatol 2010; 162: 889.

16. Fife CE, Maus EA, Carter MJ. Lipedema, a frequently misdiagnosed and misunderstood fatty deposition syndrome. Adv Skin Wound Care 2010; 23: 81-92.

17. Shelhamer JH, Volkman DJ, Parrillo JE, Lawley TJ, Johnston MR, Fauci AS. Takayasu's arteritis and its therapy. Ann Intern Med 1985; 103: 121-126.

18. Arend WP, Michel BA, Bloch DA, Hunder GG, Calabrese LH, Edworthy SM, Fauci AS, Leavitt RY, Lie JT, Lightfoot RW Jr, et al. The American College of Rheumatology 1990 criteria for the classification of Takayasu arteritis. Arthritis Rheum 1990; 33: 1129-1134. 
19. Vanoli M, Bacchiani G, Origg L, Scorza R. Takayasu's arteritis: a changing disease. J Nephrol. 2001; 14: 497-505.

20. Numano F, Okawara M, Inomata H, Kobayashi Y. Takayasu's arteritis. Lancet. 2000; 356: 1023-1025.

21. American Diabetes Association. All about diabetes. <www.diabetes.org/aboutdiabetes.jsp> (Version current at July 1, 2010)

22. World Health Organization. Diabetes programme: What is diabetes? <who.int/diabetes/BOOKLET_HTML/en/index4.html> > (Version current at July 1, 2010)

23. Devereux RB, Reichek N. Echocardiographic determination of left ventricular mass in man: Anatomic validation of the method. Circulation 1977; 55: 613-618.

24. DuBois D, DuBois EF. A formula to estimate the approximate surface area if height and weight be known. Arch Int Med 1916; 17: 863-871.

25. Devereux RB. Detection of left ventricular hypertrophy by M-mode echocardiography: anatomic validation, standardization, and comparison to other methods. Hypertension 1987; 9: II19-20.

26. Peterson LN, Jensen RE, Parnell R. Mechanical properties of arteries in vivo. Circ Res 1960; 8: 622-639.

27. Nichols WW, O'Rourke MF. Properties of the arterial wall. In McDonald's Blood Flow in Arteries. Lea\&Ferbiger, Philadelphia, 1989; 77-124.

28. Nemes A, Takacs R, Gavaller H, Várkonyi TT, Wittmann T, Forster T, Lengyel C. Correlations between Arteriograph-derived pulse wave velocity and aortic elastic properties by echocardiography. Clin Physiol Funct Imaging 2011; 31: 61-65.

29. Nemes A, Soliman OI, Geleijnse ML, Anwar AM, van der Beek NA, van Doorn PA, Gavallér H, Csajbók E, ten Cate FJ.. Increased aortic stiffness in glycogenosis type 2 (Pompe's disease). Int J Cardiol 2007; 120: 138-141. 
30. Eren M, Gorgulu S, Uslu N, Celik S, Dagdeviren B, Tezel T. Relation between aortic stiffness and left ventricular diastolic function in patients with hypertension, diabetes, or both. Heart 2004; 91: 37-43.

31. Nemes A, Forster T, Gruber N, Csanády M. Coronary flow velocity reserve and indices describing aortic distensibility in patients after coronary angiography. Int J Cardiol 2004; 96: 29-33.

32. Nemes A, Forster T, Csanády M, Gruber N. Indices of aortic distensibility and coronary flow velocity reserve in patients with different grades of aortic atherosclerosis. Int $\mathbf{J}$ Cardiac Imag 2004; 20: 271-277.

33. Nemes A, Forster T, Csanády M. Decreased aortic distensibility and coronary flow velocity reserve in patients with significant aortic valve stenosis with normal epicardial coronary arteries. J Heart Valve Dis 2004; 13: 567-573.

34. Rajzer MW, Wojciechowska W, Klocek M, Palka I, Brzozowska-Kiszka M, KaweckaJaszcz K. Comparison of aortic pulse wave velocity measured by three techniques: Complior, SphygmoCor and Arteriograph. J Hypertens 2008; 26: 2001-2007.

35. Jatoi NA, Mahmud A, Bennett K, Feely J. Assessment of arterial stiffness in hypertension: comparison of oscillometric (Arteriograph), piezoelectronic (Complior) and tonometric (SphygmoCor) techniques. J Hypertens 2009; 27: 2186-2191.

36. Nemcsik J, Egresits J, El Hadj Othmane T, Fekete BC, Fodor E, Szabó T, Járiai Z, Jekkel C, Kiss I, Tislér A. Validation of Arteriograph - A New Oscillometric Device to Measure Arterial Stiffness in Patients on Maintenance Hemodialysis. Kidney Blood Press Res 2009; 32: 223-229.

37. Trachet B, Reymond P, Kips J, Swillens A, De Buyzere M, Suys B, Stergiopulos N, Segers P. Numerical validation of a new method to assess aortic pulse wave velocity from a single recording of a brachial artery waveform with an occluding cuff. Ann Biomed Eng 2010; 38: 876-888.

38. Austin BA, Popovic ZB, Kwon DH, Thamilarasan M, Boonyasirinant T, Flamm SD, Lever HM, Desai MY. Aortic stiffness independently predicts exercise capacity in hypertrophic cardiomyopathy: a multimodality imaging study. Heart 2010; 96: 1303-1310. 
39. Soliman OI, Knaapen P, Geleijnse ML, et al. Assessment of intravascular and extravascular mechanisms of myocardial perfusion abnormalities in obstructive hypertrophic cardiomyopathy by myocardial contrast echocardiography. Heart 2007; 93: 1204-1212.

40. Dimitrow PP, Krzanowski M, Surdacki A, Nizankowski R, Szczeklik A, Dubiel JS. Impaired response of the forearm resistance but not conductance vessels to reactive hyperemia in hypertrophic cardiomyopathy. Angiology 1999; 50: 267-272.

41. Kühl HP. Hypertrophic cardiomyopathy, fibrosis and aortic stiffness. An unidentified association unraveled by magnetic resonance imaging. J Am Coll Cardiol 2010; 54: 263264.

42. Földi M, Kubik S. Textbook of lymphology. Urban and Fischer Publisher, 2005.

43. Child AH, Gordon KD, Sharpe P, Brice G, Ostergaard P, Jeffery S, Mortimer PS. Lipedema: an inherited condition. Am J Med Genet A 2010; 152A: 970-976.

44. Nemes A, Gavallér H, Csajbók E, Forster T, Csanády M. Obesity is associated with aortic enlargement and increased stiffness: an echocardiographic study. Int J Cardiovasc Imaging 2008; 24: 165-171.

45. Wildman RP, Mackey RH, Bostom A, Thompson T, Sutton-Tyrrell. Measures of obesity are associated with vascular stiffness in young and older adults. Hypertension 2003; 42: $468-473$.

46. Brunzell JD, Hokanson JE. Dyslipidemia of central obesity and insulin resistance. Diabetes Care 1999; 22 (Suppl 3): C10-C13.

47. Stenvinkel P, Bolinder J, Alvestrand A. Effects of insulin on renal haemodynamics and the proximal and distal tubular sodium handling in healthy subjects. Diabetologia 1992; 35: $1042-1048$.

48. Young JB. Effect of experimental hyperinsulinemia on sympathetic nervous system activity in the rat. Life Sci 1988; 43: 193-200.

49. Ulrich P, Cerami A. Protein glycation, diabetes, and aging. Recent Prog Horm Res 2001; 56: $1-21$. 
50. DeFronzo RA, Ferrannini E. Insulin resistance. A multifaceted syndrome responsible for NIDDM, obesity, hypertension, dyslipidemia, and atherosclerotic cardiovascular disease. Diabetes Care 1994; 14: 173-194.

51. Kahn BB, Flier JS. Obesity and insulin resistance. J Clin Invest 2000; 106: 473-481.

52. Arcaro G, Cretti A, Balzano S, Lechi A, Muqqeo M, Bonora E, Bonadonna RC. Insulin causes endothelial dysfunction in humans: sites and mechanisms. Circulation 2002; 105: $576-582$.

53. Egan BM, Lu G, Greene EL. Vascular effects of non-esterified fatty acids: implications for the cardiovascular risk factor cluster. Prostaglandins Leukot. Essent. Fatty Acids 1999; 60: 411-420.

54. Weyer C, Yudkin JS, Stehouwer CD, Schalkwijk CG, Pratley RE, Tataranni PA. Humoral markers of inflammation and endothelial dysfunction in relation to adiposity and in vivo insulin action in Pima Indians. Atherosclerosis 2002; 161: 233-242.

55. Visser M, Bouter M, McQuillan GM, Wener MH, Harris TB. Elevated C-reactive protein levels in overweight and obese adults. JAMA 1999; 282: 2131-2135.

56. Szolnoky, G, Nagy N, Kovács RK, Dósa-Rácz E, Szabó A, Bársony K, Balogh M, Kemény L. Complex decongestive physiotherapy reduces capillary fragility in lipedema. Lymphology 2008; 41: 161-166.

57. Földi E, Földi M. A comparative study to measure veno-arterial reflex in lipedema. Lipoedema and Cellulitis. Viavital Publisher 2001: 80-86.

58. Harwood CA, Bull RH, Evans J, Mortimer PS. Lymphatic and venous function in lipoedema. Br J Dermatol 1996; 134: 1-6.

59. Brauer WJ. Altersbezogene Funktionslymphszintigraphie beim Lipödem und Lipolymphödem. LypmphForsch 2000; 4: 74-77.

60. Amann-Vesti BR, Franzeck UK. Bollinger A. Microlymphatic aneurysms in patients with lipedema. Mypmhology 2001; 34: 170-175. 
61. Siems W, Grune T, Voss P, Brenke R. Anti-fibrosclerotic effects of shock wave therapy in lipoedema and cellulite. Biofactors 2005; 24: 275-282.

62. Suga H, Araki J, Aoi N, Kato H, Higashino T, Yoshimura K. Adipose tissue remodeling in lipedema: adipocyte death and concurrent regeneration. J Cutan Pathol 2009; 36: 12931298.

63. Feihl F, Liaudet L, Waeber B. The macrocirculation and microcirculation of hypertension. Curr Hypertens Rep 2009; 11: 182-189.

64. Stafanadis C, Dernellis J, Toutouzas P. Aortic elastic properties in Takayasu arteritis. Int J Cardiol 1998; 67: 273-274.

65. Eren M, Gorgulu S, Uslu N, Celik S, Dagdeviren B, Tezel T. Relation between aortic stiffness and left ventricular diastolic function in patients with hypertension, diabetes or both. Heart 2004; 90: 37-43. 


\section{Acknowledgments}

The studies reported in this work were performed in the 2nd Department of Medicine and Cardiology Center, Medical Faculty, Albert Szent-Györgyi Clinical Center, University of Szeged, Hungary.

I am especially indebted to Dr. Attila Nemes, who was my tutor and scientific adviser. Without his support and encouragement this work could not be done.

I would like to express my acknowledgement to Prof. Dr. Tamás Forster, the head of the 2nd Department of Medicine and Cardiology Center for all of his patience and support to my work.

I would like to thank Prof. Dr. Lajos Kemény, the head of Department of Dermatology and Allergology and Dr. Győző Szolnoky, who helped me to to learn a lot about lipoedema.

I am grateful to Prof. Dr. Tibor Wittmann, the head of 1st Department of Medicine and Dr. Csaba Lengyel, who helped me in organizing aortic stiffness measurements.

I would like to thank to my co-authors who gave me huge support and to the staff of the echocardiographic laboratory.

Last, but not least I would like to express my deepest gratitude to my parents who were always with me. 
Photocopies of essential publications 